\title{
Neural circuitry of impulsivity in a cigarette craving paradigm
}

\author{
Josiane Bourque ${ }^{1,2}$, Adrianna Mendrek ${ }^{1,3}$, Laurence Dinh-Williams ${ }^{1,2}$ and Stéphane Potvin ${ }^{1,2 *}$ \\ ${ }^{1}$ Centre de Recherche de I'Institut Universitaire de Santé Mentale de Montréal, Montréal, OC, Canada \\ ${ }^{2}$ Department of Psychiatry, Faculty of Medicine, University of Montreal, Montreal, QC, Canada \\ ${ }^{3}$ Department of Psychology, Bishop's University, Sherbrooke, OC, Canada
}

\section{Edited by:}

Janna Cousijn, University of

Amsterdam, Netherlands

\section{Reviewed by:}

Sabine Vollstädt-Klein, Heidelberg

University, Germany

Lindsay M. Squeglia, University of

California San Diego, USA

*Correspondence:

Stéphane Potvin, Centre de Recherche de I'Institut Universitaire de Santé Mentale de Montréal, 7331 Hochelaga, Montréal, OC H1N 3V2,

Canada

e-mail:stephane.potvin@

umontreal.ca
Impulsivity has been shown to play a pivotal role in the onset, pattern of consumption, relapse and, most notably, craving of illicit and licit drugs such as cigarette smoking. The goal of this study was to examine the neurobiological influence of trait impulsivity during cue-induced cigarette craving. Thirty-one chronic smokers passively viewed appetitive smoking-related and neutral images while being scanned and reported their feelings of craving. They completed the Barratt Impulsiveness Scale, a measure of trait impulsivity. We conducted functional connectivity analyses using the psycho-physiological interaction method. During the processing of smoking stimuli, participants presented increased activations in the cingulate and prefrontal cortices. We observed a significant positive relationship between impulsivity scores and reported craving. A negative correlation was observed between the impulsivity score and activity in the posterior cingulate cortex (PCC). The insula, dorsal anterior cingulate cortex (dACC) as well as the dorsolateral prefrontal cortex (DLPFC) presented a negative connectivity with the PCC. Consistent with the view that the PCC is related to the ability to resist cigarette craving, our results suggest that high impulsive smokers have greater difficulty in controlling their cravings, and that this weakness may be mediated by lower PCC activity. Moreover, we argue that the less PCC activity, the greater the probability of a stronger emotional, physiological, and biased attentional response to smoking cues mediated by insula, dACC, and DLPFC activity. This is the first study on this topic, and so, results will need to be replicated in both licit and illicit drug abusers. Our findings also highlight a need for more emphasis on the PCC in drug addiction research, as it is one of the most consistently activated regions in functional magnetic resonance imaging studies examining the neural correlates of cue-induced alcohol, drug, and tobacco cravings.

Keywords: craving, impulsivity, cigarette smoking, neural correlates, fMRI

\section{INTRODUCTION}

Approximately 20\% of adults in Canada and in the US smoke tobacco, and are at high risks (a three to ninefold increased risk relative to the general population) of developing cancer or pulmonary and cardiac diseases (1-3). Given its deleterious effects on health, more than half of cigarette smokers express a desire to quit (4). Unfortunately, $72-90 \%$ of smokers attempting to quit, with or without treatment, will have relapsed by 1-year following their quit date (5-7). Cessation attempts and treatment methods would be greatly ameliorated by improving understanding of the behavioral and neurobiological mechanisms underlying relapse.

Clinical research consistently demonstrates that one of the best predictors of smoking and illicit drug abuse relapse is craving $(8,9)$. Craving is a multifaceted state characterized by both automatic and non-automatic processing, the latter involving cognitive efforts to either aid or prevent the execution of automatized sequences of drug use (10-12). In abstinent and non-abstinent smokers, exposure to cigarette-associated cues and/or stress can induce a strong craving response, and therefore enhance the risk of relapse in abstinent smokers $(8,13,14)$. Over the past decade, there has been a growing interest in examining the biological roots of cue-elicited cigarette craving using functional magnetic resonance imaging (fMRI). Recent review and meta-analysis have shown that overall, in both deprived and non-deprived smokers, cigarette craving is associated with cerebral activations in the extended visual system, the superior and middle temporal gyri, the precuneus, the posterior and anterior cingulate gyri, the prefrontal and orbitofrontal cortices, the insula, as well as the dorsal striatum $(15,16)$. However, when looking at each individual study, we found that several factors can contribute to the heterogeneity of findings between studies, notably smoking expectancy and abstinence levels (17-21).

Moreover, there is also a strong between subject variability within studies in the overall brain activations associated with exposure to smoking cues (22) and more specifically, in terms of the peak activity location for each participants (23). It is crucial to further understand this variability in brain reactivity to cigarette stimuli and craving response. To our knowledge, only nicotine 
dependence severity, sex, one's degree of discontent toward his/her smoking behavior and genetic factors (e.g., dopamine transporter) have been studied as potential factors implicated in cigarette craving brain responses $(22,24-26)$. For instance, nicotine dependence severity was associated with specific cerebral activations in four out of five studies $(24,25,27-29)$. In the present study, we wished to examine if the reward-related personality trait of impulsivity, which has been shown to play a key role in addiction (cigarette, alcohol, cocaine), influences the pattern of brain activity observed during an appetitive smoking-related state.

Impulsivity traits have been (1) consistently associated with drug abuse and smoking behavior. Current smokers compared to non- and former-smokers present higher scores of impulsivity (30, 31 ). In addition, cognitive measures of impulsivity such as inattention, disinhibition, and impulsive decision-making are related to smoking status in both adolescents and adults $(30,32,33)$. Impulsivity has also been shown to be (2) a good predictor of the onset and increase of substance use in early adolescence $(34,35)$. In the case of smoking, results have been less consistent, however a number of studies have suggested that hyperactivity/impulsivity predict tobacco smoking in adolescents (36). Finally, (3) smoking relapse is influenced by personality traits. Several studies have reported that following a 1 - to 2 -month cessation program, highly impulsive adolescent smokers were less successful in quitting than non-impulsive smokers $(37,38)$. Furthermore, experimental studies have shown that during abstinence, those with high levels of trait impulsivity present significantly greater cravings and positive reinforcement expectancies from smoking, relative to low impulsive smokers (39-41).

Therefore, the main purpose of this study was to explore the association between trait impulsivity and the neural correlates of cue-elicited cigarette craving. To our knowledge, this is the first study to investigate this topic. We examined impulsivity as a broad construct, such as a personality trait, rather than components that reflect impulsivity (e.g., response inhibition). Among the brain regions involved in nicotine craving, the dorsolateral prefrontal cortex (DLPFC), the orbitofrontal cortex (OFC) as well as the dorsal anterior cingulate cortex (dACC) all play a significant role in self-control processes, such as executive control and adaptive responding. These structures have been shown to be functionally impaired in substance abusers and cigarette smokers (42-46) and thus, have been hypothesized as important structures in the maintenance of addictive behavior. Additionally, various regions of the cingulate cortex have been directly implicated in resisting cigarette craving (47-49). Despite the exploratory nature of this work, we expected to find a positive correlation between cue ratings of craving and impulsivity; a negative correlation between trait impulsivity and brain regions underlying impulse control; and a negative coupling (functional connectivity) between impulsecontrol areas and brain regions responsible for attributing salience to smoking-related cues.

\section{MATERIALS AND METHODS \\ PARTICIPANTS}

Thirty-one healthy smokers ( 15 men) were recruited through the research center and affiliated hospital, as well as using Internet advertisements. Participants were chronic smokers (between 12 and 33 cigarettes/day; mean: 19.3; SD: 5.7) not currently seeking treatment, aged $18-55$ years old (mean: 31.8 ; SD: 9.2), righthanded (except for 1 ambidextrous and 1 left-handed), Caucasian $(84 \%)$, with no concomitant neurological, axis I or axis II disorder (based on self-report of previous diagnosis); and no contraindications for MRI. The average number of years of education was 12.9 (SD: 2.7 ). None of the participants received psychiatric or neurologic drug treatment. Participants had been smoking cigarette for an average of 15.9 years (SD: 9.6) prior, with their first cigarette at 16.0 (SD: 3.4 ) years of age, and had tried quitting an average of 2.7 times (SD: 2.7 ).

Nicotine dependence severity was assessed using the Fagerström Test for Nicotine Dependence (FTND) (50), and cigarette craving with the French Tobacco Craving questionnaire (FTCQ12) (51) prior to scanning. In addition, our group was required to fill the Readiness to Quit Ladder questionnaire (52) on a scale from 1 (I have decided not to quit smoking for my lifetime. I have no interest in quitting) to 10 (I have quit smoking); participants were instructed to choose the number that represents his or her present state best. We administered the Beck Depression Inventory (BDI) (53) and the State-Trait Anxiety Inventory (STAI) (54) as measures of depression and anxiety symptoms respectively. Lastly, the participants completed the Barratt Impulsiveness Scale (BIS-11), a measure of impulsive personality traits (55).

In agreement with the Declaration of Helsinki, written informed consent was obtained from each participant prior to the testing sessions. The study was approved by the ethics committee of the Réseau de Neuroimagerie du Québec.

\section{fMRI PROCEDURE}

Thirty to 40 min prior to each fMRI scanning session, participants were invited to smoke a cigarette to minimize withdrawal effects and standardize the period of non-smoking. While in the scanner, following the anatomical acquisition, participants passively viewed an alternating sequence of appetitive smoking-related images from the International Smoking Image Series (ISIS) (56) and neutral pictures taken from the International Affective Picture System (IAPS) (57). Neutral IAPS pictures were matched with the smoking-related images (ISIS) for visual complexity, color, and number of faces and body parts.

During the scanning session, participants were instructed to press a button when a picture appeared in order to monitor their level of attention. The task consisted of an alternating sequence of five experimental (appetitive smoking-related images) and five control condition blocks (neutral pictures) with 10 periods of rest separating the blocks from one another. The rest period consisted of a 15-s blank screen with a fixation cross. Each block lasted $25 \mathrm{~s}$ and consisted of five pictures, presented for $4 \mathrm{~s}$ each. There was an inter-stimulus interval (blank screen) of an average of $1 \mathrm{~s}$ (ranging from 0.5 to 1.5 ) presented before each picture. Within a block, images were randomly presented. Participants viewed a total of 25 appetitive as well as 25 neutral pictures.

At the end of the fMRI session, participants were re-presented with the smoking-related and neutral images, and were asked to rate them on a scale from 0 (images elicit no desire to smoke a cigarette) to 100 (images elicit the strongest desire to smoke ever experienced). 


\section{IMRI DATA ACOUISITION}

We recorded blood oxygenation level dependent signals using a single-shot, gradient-recalled echo-planar imaging sequence (repetition time $=3000 \mathrm{~ms}$, echo time $=30 \mathrm{~ms}$, flip angle $=90^{\circ}$, matrix size $=64 \times 64$ voxels, field of view $=224 \mathrm{~mm}$, number of slices $=41$, slice thickness $=3.5 \mathrm{~mm}$, interslice gap $=$ no gap, voxels size $=3.5 \mathrm{~mm} \times 3.5 \mathrm{~mm} \times 3.5 \mathrm{~mm}$ ) on a Siemens TRIO MRI system at 3.0 Tesla at the Functional Neuroimaging Unit at the University of Montreal Geriatric Institute. We then registered the whole brain functional volumes to individual high-resolution co-planar anatomical images taken during the same scanning session (three-dimensional, ultrafast gradient echo sequence; repetition time $=2300 \mathrm{~ms}$, echo time $=2.98 \mathrm{~ms}$, flip angle $=9$, matrix size $=256 \times 256$ voxels, number of slices $=176$, voxels size $=1.0 \mathrm{~mm} \times 1.0 \mathrm{~mm} \times 1.0 \mathrm{~mm})$.

\section{fMRI DATA ANALYSIS}

We analyzed fMRI data using a statistical parametric mapping software (SPM5: Wellcome Department of Cognitive Neurology, London, UK) according to the methods outlined by Friston (58). The functional images were realigned to the mean volume of the run to correct for artifacts due to minor head movements, high-pass filtered, spatially normalized into the standardized T1 brain template, and spatially smoothed with a three-dimensional isotropic Gaussian kernel ( $8 \mathrm{~mm}$ FWHM) to improve signal-to-noise ratio.

We used a standard peak-detection approach and the general linear model implemented in SPM5 for our statistical analyses in order to identify the dynamic cerebral changes associated with cigarette craving, using a block design. First, we undertook a fixedeffects analysis for each participant to investigate individual brain activation maps associated with our contrasts of interest (appetitive smoking-related minus neutral material, and vice versa). A second-level random-effects model was then implemented to investigate the pattern of activations during both contrasts (i.e., appetitive minus neutral material and neutral minus appetitive material) in our group, using a one-sample $t$-test. We performed region-of-interest (ROI) analyses, using the "small volume correction" option of SPM at a threshold of $p<0.05$, false discovery rate (FDR) corrected for multiple comparisons. The small volume was chosen using a sphere (radius $=12 \mathrm{~mm}$ ) located in the center of the corresponding region according to the Automated Anatomical Labeling atlas (59). Our ROIs included the medial and DLPFC; anterior, middle, and posterior cingulate gyri; OFC; dorsal striatum; precuneus as well as the insula. In addition, using the Volume of Interest tool in SPM, we extracted the first eigenvariate from the one-sample $t$-test (for the contrast: appetitive smoking-related minus neutral material) based on the center of each ROI clusters identified by SPM. We then performed Pearson correlation analyses with the Statistical Package for the Social Sciences (SPSS) to investigate the association between the impulsivity score from the BIS-11 and first eigenvariates of each ROI, and also between cue ratings of craving and first eigenvariates of each ROI. To investigate the extensive relationship between impulsivity and ROI activations, we used the psycho-physiological interaction (PPI) method, a multiple regression technique that allows the investigation of the functional coupling between regions in relation to the experimental paradigm (60). Consequently, for each
ROI (those significantly correlated with the impulsivity score) we extracted the first eigenvariate time series from each participant using the Volume of Interest tool in SPM. The PPI regressor was calculated as the element by element product of the ROI time series and a vector coding for the effect of task (craving minus neutral condition). This interaction term was then entered as a regressor of interest in a first level model together with the ROI time series and the vector coding for the task effect. Ultimately, model contrasts were generated to test the effects of positive and negative PPIs. Given the paucity of studies investigating functional connectivity in addiction, we set the threshold level for statistical significance at $p<0.001$ (uncorrected). For all types of analyses, we considered extent thresholds of 20 contiguous voxels.

\section{BEHAVIORAL DATA ANALYSES}

We performed Pearson correlation analyses between the impulsivity score (total and second order factors) on the BIS-11 and ratings of craving with SPSS.

\section{RESULTS}

\section{SELF-REPORT}

As displayed in Table 1, participants presented minimal symptoms of anxiety and depression. In general, participants were moderately dependent on nicotine, had moderate level of cravings and their motivation to quit corresponded to: I often think about quitting smoking, but I have no plans to quit. Finally, they presented a mean impulsivity level in normal limits. When looking at the appetitive smoking images from the task, participants rated the intensity of their craving at $47.1 \%$ (SD: 27.9) of strongest desire ever experienced.

We observed a significant positive correlation between the total impulsivity score on the BIS-11 and the reported craving from the smoking-related images $(r=0.624 ; p<0.001)$. Among second order factors (attentional, motor, and non-planning) of the BIS, it was the non-planning subscale which was the most significantly positively correlated with the ratings of craving $(r=0.625$; $p<0.001)$.

\section{fMRI}

\section{One-sample t-test}

For the appetitive smoking-related minus neutral contrast, ROI analyses revealed significant loci of cerebral activations in the anterior cingulate gyrus bilaterally, the right medial superior frontal gyrus, the left superior frontal gyrus, and the left posterior cingulate gyrus. Conversely, we found no significant loci of activations

Table 1 | Demographic data. Standard deviation (SD) in parentheses.

\begin{tabular}{lr}
\hline Questionnaires & Mean results \\
\hline STAI (State-trait anxiety inventory) & 35.6 (SD: 8.0) \\
BDI (Beck depression inventory) & 5.3 (SD: 6.0) \\
FTND (Fagerström test for nicotine dependence) & 4.3 (SD: 2.6) \\
FTCQ-12 (French tobacco craving questionnaire) & 3.6 (SD: 1.0) \\
Readiness to quit ladder & 5.2 (SD: 1.3) \\
BIS-11 (Barratt impulsiveness scale) & 63.7 (SD: 10.8)
\end{tabular}


Table 2 | ROI activations during viewing of appetitive cigarette and neutral images.

\begin{tabular}{|c|c|c|c|c|c|c|c|c|}
\hline \multirow[t]{2}{*}{ Brain region } & \multirow[t]{2}{*}{$R / L$} & \multirow[t]{2}{*}{ BA } & \multicolumn{3}{|c|}{ MNI coordinates } & \multirow[t]{2}{*}{ z-Score } & \multirow[t]{2}{*}{ Voxels } & \multirow[t]{2}{*}{$p$-Value } \\
\hline & & & $\boldsymbol{x}$ & $y$ & $z$ & & & \\
\hline \multicolumn{9}{|l|}{ SMOKING > NEUTRAL } \\
\hline \multirow[t]{2}{*}{ Anterior cingulate gyrus } & $L$ & 32 & -1 & 42 & -4 & 3.54 & 170 & 0.008 \\
\hline & $\mathrm{R}$ & 24 & 4 & 38 & 7 & 3.48 & $170^{*}$ & 0.008 \\
\hline Medial superior frontal gyrus & $\mathrm{R}$ & 10 & 14 & 66 & 10 & 3.43 & 24 & 0.025 \\
\hline Superior frontal gyrus & $L$ & 9 & -14 & 46 & 38 & 3.32 & 24 & 0.038 \\
\hline Posterior cingulate gyrus & $L$ & 31 & -4 & -52 & 32 & 3.27 & 84 & 0.021 \\
\hline
\end{tabular}

$R$, right; L, left; BA, Brodmann area; *same cluster as above; p-value is FDR corrected at $<0.05$.

Neutral> smoking.

No significant activations in the ROIs.

in our ROIs for the neutral minus appetitive smoking-related contrast (Table 2; Figure 1).

\section{Correlations}

We found no correlation between cue ratings of cravings and activations in any of our ROIs for the appetitive smoking minus neutral contrast. However, as shown in Figure 2, there was a significant negative correlation between the total impulsivity score on the BIS11 and activity in the left posterior cingulate gyrus $(r=-0.449$; $p=0.015$ ). More specifically, among the second order factors of impulsivity only the non-planning subscale presented a significant negative relationship with the posterior cingulate gyrus $(r=-0.440 ; p=0.017)$. The posterior cingulate gyrus was therefore used as the seed region for the PPI analyses. Impulsivity (total and subscale scores) was not correlated with any other brain region.

\section{Psycho-physiological interaction}

We used the PPI method to explore the functional coupling of the posterior cingulate gyrus, and found that the left insula (MNI coordinates: $x=-28 ; y=10 ; z=18 ; 126$ voxels; $z=3.81 ; p<0.001$ ), the right middle frontal gyrus [MNI coordinates: $x=28 ; y=21$; $z=35$; Broadmann area $(\mathrm{BA})=9 ; 227$ voxels; $z=3.74 ; p<0.001$ ] and the right dACC (MNI coordinates: $x=7 ; y=24 ; z=24$; $\mathrm{BA}=24 ; 25$ voxels; $z=3.60 ; p<0.001)$ presented significant negative connectivity with the posterior cingulate gyrus, as shown in Figure 3. There were no significant positive connectivity between the posterior cingulate gyrus and any region of the brain.

\section{DISCUSSION}

As craving and impulsivity traits are both strong predictors of relapse, the aim of the present study was to explore the neural correlates underlying their relationship in chronic tobacco smokers. Similarly to previous neuroimaging studies on drug cue-reactivity, we reported significant activations in regions of the cingulate and prefrontal cortices during the processing of appetitive smokingrelated stimuli $(15,16)$. We also found important correlations between impulsivity traits and both behavioral and neurobiological measures of craving. Accordingly, impulsivity was (1) positively correlated with the reported craving from the fMRI task and (2) negatively associated with the activity of the posterior

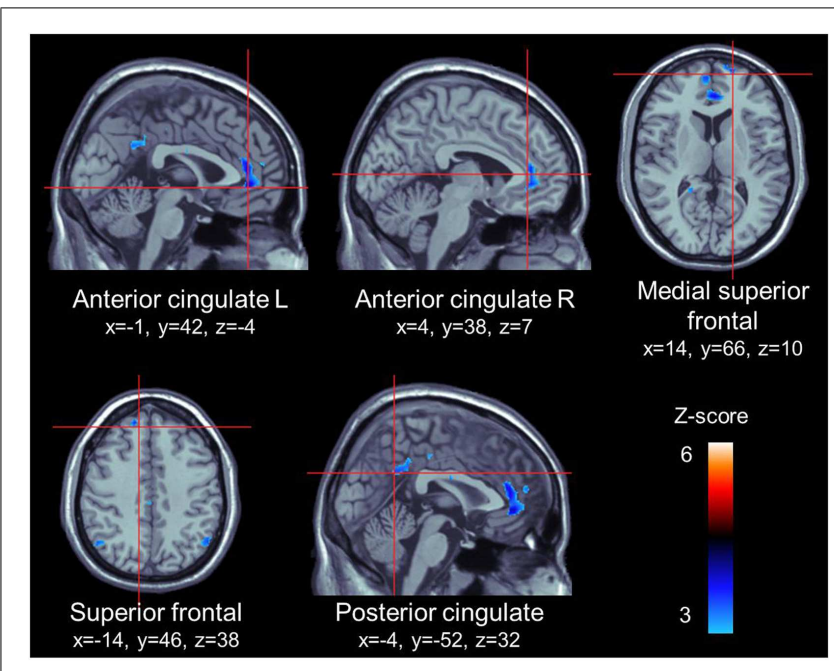

FIGURE 1 | ROI activations during viewing of appetitive cigarette images (relative to neutral images). All highlighted regions in this figure were significantly activated. Transition from blue to red color represents increases in $z$-scores.

cingulate cortex (PCC) during cigarette cue response. Finally, functional connectivity analyses revealed that the activity of the insula, DLPFC and dACC were negatively correlated with that of the PCC during cue-elicited craving.

The processing of appetitive cigarette smoking relative to neutral stimuli elicited significant loci of activations distributed in regions of the cingulate gyrus (bilateral ventral part of the anterior cingulate cortex and left PCC) and the prefrontal cortex (right medial superior and left superior frontal cortices). The anterior cingulate and prefrontal cortices are the two most consistently reported structures in cigarette craving studies (16). The ventral part of the anterior cingulate cortex, known as the affective region, is involved in regulating emotional responses (61) and more specifically, assessing the salience of emotional and motivational information, such as drug-related cues (62). The medial prefrontal cortex is widely implicated in self-related processes (63, 64) and of note, various authors have found that self-referential processing of cues (medial prefrontal cortex activity) enhances 
learning and promotes behaviors oriented toward the content of these cues (65-67). Therefore, it is possible that the activity observed in the medial prefrontal cortex during smoking cues reflects self-related processing, and promotes smoking behavior. The PCC has been repeatedly activated during cue-elicited cigarette craving, but have received far less attention (16). This region has been linked to attentional tracking of stimuli, memory recall and, similarly to the medial prefrontal cortex, self-referential, and reflective activity $(16,63,68,69)$. Thus, the response to smoking cues observed in this study may be reflective of smokers' attentional bias toward smoking cues, its self-relevance and emotional salience, memory of its incentive value, and preparing for the physical act of smoking.

On a behavioral level, the total score of impulsivity presented a strong positive relationship with the cue ratings of craving. These

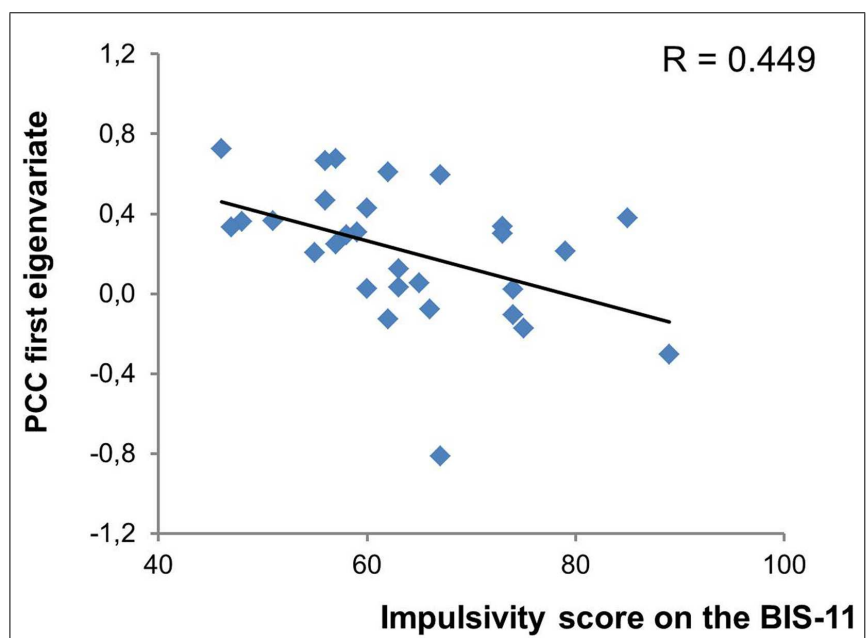

FIGURE 2 | Significant relationship between impulsivity levels and posterior cingulate cortex activity. $\mathrm{PCC}$, posterior cingulate cortex. results are in accordance with a vast array of clinical and experimental studies showing a positive correlation between impulsivity and alcohol $(70-72)$, nicotine $(73,74)$, as well as cocaine and methamphetamines craving (75). What's more, between the three different second order factors of the BIS-11, the non-planning factor had the strongest association with the reported craving. As this factor involves a lack of reflection, self-control, and forethought (76), our results corroborate the importance of these cognitive factors in addictive behavior and a craving response. Indeed, relative to conditioning-based models of craving, cognitive views emphasize the necessity of non-automatic processes for overriding automatic drug use patterns (e.g., to halt the execution of automatized drug use acts) $(10,11)$. Therefore, we suggest that increasing levels of trait impulsivity and poor planning abilities/self-control in cigarette smokers is related to diminished capacities to suppress these automatic drug thoughts and urges.

Our neuroimaging results demonstrated no direct association between subjective craving and brain activations during the processing of cigarette cues (versus neutral images). Nevertheless, we observed a strong negative relationship between the total score of trait impulsivity and activity in the left PCC during response to smoking stimuli (versus neutral images). Among the second order factors of the BIS-11, non-planning covaried negatively with the PCC. This result suggests that increasingly poor levels of self-control and self-reflection are associated with decreased fMRI signal in the PCC, compared to less impulsive smokers. Consistent with our finding, the PCC is related to the ability to resist cigarette cravings. Brody et al. (47) found that activity in the left PCC was greater while participants were actively trying to suppress their urge to smoke than while allowing themselves to crave. It is possible then that individuals with poor planning abilities/self-control experience greater difficulty in controlling their cravings, and that this weakness may be mediated by lower PCC activity. Of note, we did not observe any direct relationship between impulsivity measures and activity in the DLPFC or OFC, which are commonly reported as centers of impulse control in studies examining the

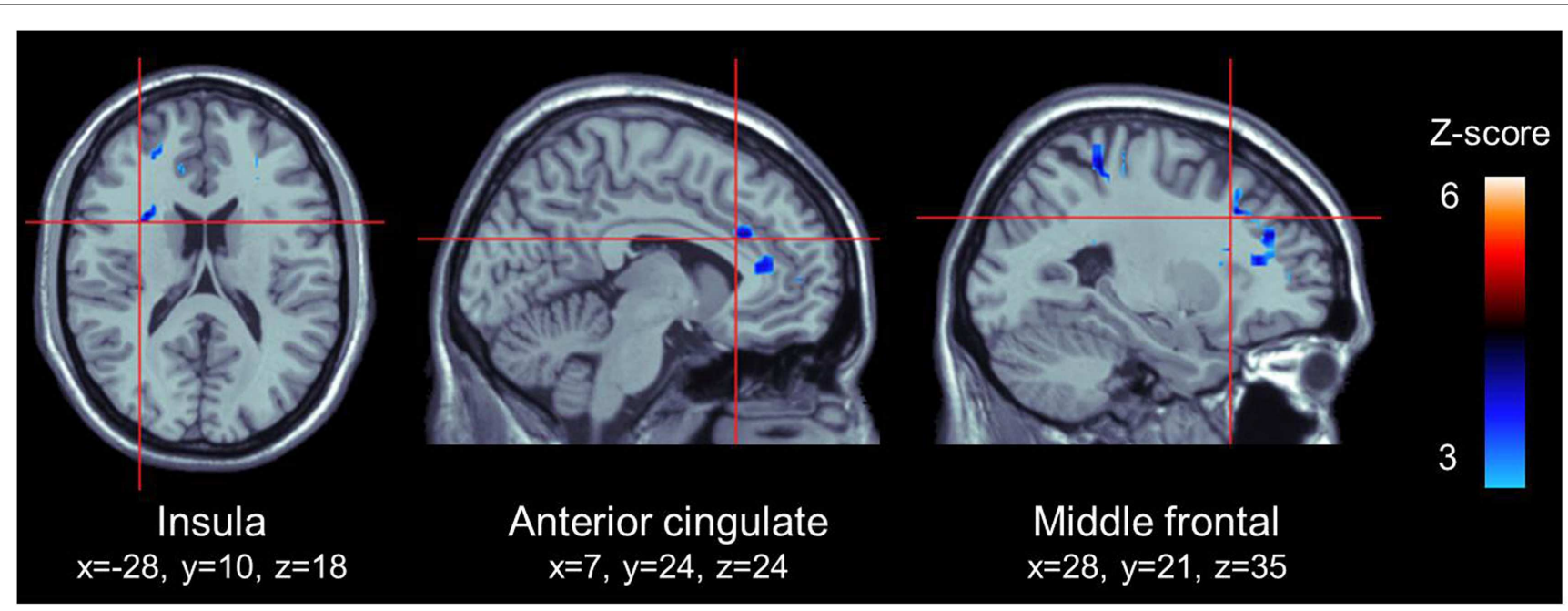

FIGURE 3 | ROI that presented a significant negative connectivity with the posterior cingulate cortex. All highlighted regions in this figure were significantly activated. Transition from blue to red color represents increases in $z$-scores. 
neurophysiologic basis of impulsivity, using decision-making or response inhibition tasks $(77,78)$. These studies however also report activity in the PCC during these tasks (79-81). Research has shown, for instance, that increased activity in the PCC during behavioral measures of impulsivity, such as a Go/NoGo task, is related to response inhibition $(80,81)$, but further investigation revealed that the PCC function was specific during incorrect NoGo versus correct ones (79). Moreover, it must be considered that fMRI studies on decision-making and response inhibition measure small-scale behavioral components of impulsivity rather than habitual patterns of behavior, thought, and emotion. It is possible that impulsivity as a trait refers to more complex neural processes (e.g., interaction between the PCC and DLPFC) than those implicated in transient decision-making or response inhibition events. Importantly, the PCC has been systematically reported in fMRI meta-analytic studies of cigarette, alcohol, and illicit drug craving (16, 82-84). Highly impulsive individuals are stimulus-bound and focus on the immediate environment and circumstances rather than long term events. This behavior illustrates a lack of introspection and mentalizing. The PCC is critical, over and above the OFC and DLPFC, for self-relevant processes such as mindfulness, mentalization, and self-reflection that promote mental exploration as well as build cognitive and affective control (85-87). Furthermore, an altered functional connectivity of the PCC with other frontal regions was demonstrated in psychiatric disorders characterized by high levels of impulsivity (88-90). The PCC may be a key structure underlying impulsivity and warrants more attention.

To further explore the mechanisms underlying the relationship between impulsivity/non-planning and the PCC, we conducted functional connectivity analyses. Using a liberal statistical threshold, the PPI analyses revealed significant negative connectivity between the PCC and the left anterior insula, the right DLPFC (BA 9) as well as the right dACC (BA 24). Noteworthy, the left anterior insula was activated during the appetitive smoking-related versus neutral contrast, but not reported here in the present study due to a low cluster threshold ( $>5$ contiguous voxels). The more anterior parts of the insula are specifically recruited during the regulation of the physiological and emotional body response to stimuli $(91,92)$, while the DLPFC and dACC are directly implicated in allocating and coordinating attentional resources for cognitive tasks (9395). We argue that the more impulsive the smoker, the greater the probability of a decrease in PCC activation and increase in insula, DLPFC, and dACC activity. This may result in a decrease of the self-reflection processes necessary for self-control and may intensify the emotional, physiological, and biased attentional response to smoking cues. Indeed, the PCC and the dACC are anatomically linked by the cingulum bundle, an important white matter fiber tract connecting limbic-cortical networks. Although the literature on functional connectivity in addiction is limited, a few preliminary studies have shown a negative relationship between the activity of the PCC and dACC. Both methamphetamine abusers and chronic smokers present inversed activations/glucose metabolism in the PCC and dACC while executing vigilance tasks $(96,97)$. Similarly, some authors have underlined an abnormal connectivity between the PCC and the anterior part of the insula in heroin addicts (98) as well as between the PCC and DLPFC in recently abstinent cocaine addicts during negative emotional experience (100). Altogether, these preliminary results propose a neural pathway for an exacerbated feeling of craving in highly impulsive cigarette smokers.

Overall, the results of our study may have implications for the understanding of the neural relationship between the rewardrelated personality trait of impulsivity and cue-elicited craving. Importantly, both impulsivity and craving are phenotypes that have become major targets of psychological, pharmacological, and brain stimulation interventions in the field of addiction (46, 99, $101,102)$, and the brain stimulation literature has recently raised the possibility that the mechanisms underlying impulsivity and craving may partially overlap $(46,103)$. However, a few limitations must be considered. Indeed, the PPI results need to be cautiously interpreted because these analyses do not allow determining the direction of the relationship between the PCC and the insula, DLPFC as well as the dACC. Here, the activity of the PCC was negatively correlated with the activity of these structures, however we do not know if it is the reduced activity within the PCC observed in highly impulsive smokers that lifts inhibition toward these structures, or it is the activation of the insula, DLPFC, and dACC that down regulate PCC function. Additionally, both the AACC and DLPFC, which presented a negative connectivity with the PCC were not significantly activated during smoking cue responses. One plausible explanation is that our participants had not been abstinent overnight for the study (they smoked 30-40 min prior to the fMRI session). For instance, important evidences have underlined that compared to relatively non-deprived smokers, overnight deprived smokers present significantly greater activations, amongst other regions, in the DLPFC and regions of the cingulate cortex $(16,21)$. Finally, the brain response to smoking cues could, in part, be influenced by the participants' simple motor task (i.e., press of a button) during viewing of appetitive and neutral pictures (104). However, here, we did not observe any activation in premotor and motor areas, even in exploratory analyses.

Although there is a vast array of clinical and experimental literature on the relationship between impulsivity traits and drug craving, this is the first study to examine the neural correlates underlying their relationship. This exploratory work reveals the neurobiological mechanisms by which impulsive traits influence the brain response to smoking cues. As impulsivity is both a solid indicator of relapse and a core feature of smoking behavior, our findings are relevant from a cessation treatment point of view. In effect, present results combined with several other findings support the necessity of treatment interventions based on rewardrelated personality traits such as impulsivity to alleviate feelings of craving and propose a potential pathway, that needs to be investigated further, by which impulsivity and craving interact. For the moment, our results will need to be replicated in chronic smokers as well as in patients abusing other psychoactive substances, and should encourage further research on the PCC in drug addiction, which remains poorly understood at the moment, although it is one of the most consistently activated regions in fMRI studies examining the neural correlates of cue-elicited alcohol, drug, and tobacco cravings. 


\section{ACKNOWLEDGMENTS}

This study was funded by grants from Canadian Institutes of Health Research (Stéphane Potvin) and the Fonds de Recherche du Québec

\section{REFERENCES}

1. King BA, Dube SR, Tynan MA. Current tobacco use among adults in the United States: findings from the National Adult Tobacco Survey. Am J Public Health (2012) 102:11. doi:10.2105/AJPH.2012.301002

2. Wong SL, Shields M, Leatherdale S, Malaison E, Hammond D. Assessment of validity of selfreported smoking status. Health Rep (2012) 23:1.

3. Jha $\mathrm{P}$, Ramasundarahettige $\mathrm{C}$, Landsman V, Rostron B, Thun M, Anderson RN, et al. 21st-century hazards of smoking and benefits of cessation in the United States. $N$ Engl J Med (2013) 368:4. doi:10.1056/NEJMsa1211128

4. Lindstrom M. Desire to stop smoking among intermittent and daily smokers: a populationbased study. Tob Control (2001) 10:4. doi:10.1136/tc.10.4.396

5. Norregaard J, Tonnesen P, Simonsen K, Petersen L, Sawe U. Smoking habits in relapsed subjects from a smoking cessation trial after one year. $\mathrm{Br} J$ Addict (1992) 87:8. doi:10.1111/j.13600443.1992.tb02006.x

6. Ferguson J, Bauld L, Chesterman J, Judge K. The English smoking treatment services: one-year outcomes. Addiction (2005) 100(Suppl 2). doi:10.1111/j.13600443.2005.01028.x

7. Cosci F, Corlando A, Fornai E, Pistelli F, Paoletti P, Carrozzi L. Nicotine dependence, psychological distress and personality traits as possible predictors of smoking cessation. Results of a double-blind study with nicotine patch. Addict Behav (2009) 34:1. doi:10.1016/ j.addbeh.2008.08.003

8. Shiffman S, Engberg JB, Paty JA, Perz WG, Gnys M, Kassel JD, et al. A day at a time: predicting smoking lapse from daily urge. J Abnorm Psychol (1997) 106:1. doi:10.1037/0021843X.106.1.104

9. Paliwal P, Hyman SM, Sinha R. Craving predicts time to cocaine relapse: further validation of the Now and Brief versions of the cocaine craving questionnaire. Drug Alcohol Depend (2008) 93:3. doi:10.1016/ j.drugalcdep.2007.10.002
10. Tiffany ST. Cognitive concepts of craving. Alcohol Res Health (1999) 23:3.

11. Tiffany ST, Conklin CA. A cognitive processing model of alcohol craving and compulsive alcohol use. Addiction (2000) 95(Suppl 2). doi:10.1046/j.13600443.95.8s2.3.x

12. Skinner MD, Aubin HJ. Craving's place in addiction theory: contributions of the major models. Neurosci Biobehav Rev (2010) 34:4. doi:10.1016/ j.neubiorev.2009.11.024

13. Abrams DB, Monti PM, Carey KB, Pinto RP, Jacobus SI. Reactivity to smoking cues and relapse: two studies of discriminant validity. Behav Res Ther (1988) 26:3. doi:10.1016/00057967(88)90003-4

14. Bedi G, Preston KL, Epstein DH, Heishman SJ, Marrone GF, Shaham Y, et al. Incubation of cue-induced cigarette craving during abstinence in human smokers. Biol Psychiatry (2011) 69:7. doi:10.1016/ j.biopsych.2010.07.014

15. Azizian A, Monterosso J, O’Neill J, London ED. Magnetic resonance imaging studies of cigarette smoking. Handb Exp Pharmacol (2009) 192. 5_5

16. Engelmann JM, Versace F, Robinson JD, Minnix JA, Lam CY, Cui Y, et al. Neural substrates of smoking cue reactivity: a meta-analysis of fMRI studies. Neuroimage (2012) 60:1. doi:10.1016/ j.neuroimage.2011.12.024

17. Wilson SJ, Sayette MA, Delgado MR, Fiez JA. Instructed smoking expectancy modulates cue-elicited neural activity: a preliminary study. Nicotine Tob Res (2005) 7:4. doi:10.1080/14622200500185520

18. McBride D, Barrett SP, Kelly JT, Aw A, Dagher A. Effects of expectancy and abstinence on the neural response to smoking cues in cigarette smokers: an fMRI study. Neuropsychopharmacology (2006) 31:12. doi:10.1038/sj.npp.1301075

19. David SP, Munafo MR, JohansenBerg H, Mackillop J, Sweet LH, Cohen RA, et al. Effects of acute nicotine abstinence doi:10.1007/978-3-540-69248-

en Santé (Stéphane Potvin). Stéphane Potvin is holder of a Junior 1 Young Investigator Award from the Fonds de la Recherche du Québec en Santé.

on cue-elicited ventral striatum/nucleus accumbens activation in female cigarette smokers: a functional magnetic resonance imaging study. Brain Imaging Behav (2007) 1:3-4. doi:10.1007/ s1 1682-007-9004-1

20. Gloria R, Angelos L, Schaefer HS, Davis JM, Majeskie M, Richmond BS, et al. An fMRI investigation of the impact of withdrawal on regional brain activity during nicotine anticipation. Psychophysiology (2009) 46:4. doi:10.1111/j.14698986.2009.00823.x

21. McClernon FJ, Kozink RV, Lutz AM, Rose JE. 24-h smoking abstinence potentiates fMRIBOLD activation to smoking cues in cerebral cortex and dorsal striatum. Psychopharmacology (Berl) (2009) 204:1. doi:10.1007/ s00213-008-1436-9

22. Franklin TR, Lohoff FW, Wang Z, Sciortino N, Harper D, Li Y, et al. DAT genotype modulates brain and behavioral responses elicited by cigarette cues. Neuropsychopharmacology (2009) 34:3. doi:10.1038/npp.2008.124

23. Hanlon CA, Jones EM, Li X, Hartwell KJ, Brady KT, George MS. Individual variability in the locus of prefrontal craving for nicotine: implications for brain stimulation studies and treatments. Drug Alcohol Depend (2012) 125:3. doi:10.1016/ j.drugalcdep.2012.02.019

24. McClernon FJ, Kozink RV, Rose JE. Individual differences in nicotine dependence, withdrawal symptoms, and sex predict transient fMRI-BOLD responses to smoking cues. Neuropsychopharmacology (2008) 33:9. doi:10.1038/sj.npp.1301618

25. Vollstadt-Klein S, Kobiella A, Buhler M, Graf C, Fehr C, Mann $\mathrm{K}$, et al. Severity of dependence modulates smokers' neuronal cue reactivity and cigarette craving elicited by tobacco advertisement. Addict Biol (2011) 16:1. doi:10.1111/j.13691600.2010.00207.x

26. Stippekohl B, Winkler $\mathrm{MH}$, Walter B, Kagerer S, Mucha RF, Pauli P, et al. Neural responses to smoking stimuli are influenced by smokers' attitudes towards their own smoking behaviour. PLoS One (2012) 7:e46782. doi:10.1371/ journal.pone.0046782

27. Smolka MN, Buhler M, Klein S, Zimmermann U, Mann K, Heinz A, et al. Severity of nicotine dependence modulates cue-induced brain activity in regions involved in motor preparation and imagery. Psychopharmacology (Berl) (2006) 184:3-4. doi:10.1007/ s00213-005-0080-X

28. Yalachkov Y, Kaiser J, Naumer MJ. Brain regions related to tool use and action knowledge reflect nicotine dependence. J Neurosci (2009) 29:15 doi:10.1523/JNEUROSCI.489108.2009

29. Goudriaan AE, de Ruiter MB, van den Brink W, Oosterlaan J, Veltman DJ. Brain activation patterns associated with cue reactivity and craving in abstinent problem gamblers, heavy smokers and healthy controls: an fMRI study. Addict Biol (2010) 15:4. doi:10.1111/j.1369 1600.2010.00242.x

30. Spinella M. Correlations between orbitofrontal dysfunction and tobacco smoking. Addict Biol (2002) 7:4. doi:10.1080/ 1355621021000005964

31. Peters J, Bromberg U, Schneider S, Brassen S, Menz M, Banaschewski $\mathrm{T}$, et al. Lower ventral striatal activation during reward anticipation in adolescent smokers. Am J Psychiatry (2011) 168:5. doi:10.1176/ appi.ajp.2010.10071024

32. Mitchell SH. Measuring impulsivity and modeling its association with cigarette smoking. Behav Cogn Neurosci Rev (2004) 3:4 doi:10.1177/1534582305276838

33. Reynolds B, Richards JB, Horn K, Karraker K. Delay discounting and probability discounting as related to cigarette smoking status in adults. Behav Processes (2004) 65:1. doi:10.1016/S03766357(03)00109-8

34. Crawford AM, Pentz MA, Chou CP, Li C, Dwyer JH. Parallel developmental trajectories of sensation seeking and regular substance use in adolescents. Psychol Addict Behav (2003) 17:3. doi:10.1037/0893164X.17.3.179 
35. Ernst M, Luckenbaugh DA, Moolchan ET, Leff MK, Allen R, Eshel N, et al. Behavioral predictors of substance-use initiation in adolescents with and without attention-deficit/hyperactivity disorder. Pediatrics (2006) 117:6. doi:10.1542/peds.2005-0704

36. Korhonen T, Levalahti E, Dick DM, Pulkkinen L, Rose RJ, Kaprio J, et al. Externalizing behaviors and cigarette smoking as predictors for use of illicit drugs: a longitudinal study among Finnish adolescent twins. Twin Res Hum Genet (2010) 13:6. doi:10.1375/twin.13.6.550

37. Doran N, Spring B, McChargue D, Pergadia M, Richmond M. Impulsivity and smoking relapse. Nicotine Tob Res (2004) 6:4. doi:10.1080/ 14622200410001727939

38. Wegmann L, Buhler A, Strunk M, Lang P, Nowak D. Smoking cessation with teenagers: the relationship between impulsivity, emotional problems, program retention and effectiveness. Addict Behav (2012) 37:4. doi:10.1016/ j.addbeh.2011.12.008

39. Netter P, Hennig J, Roed IS. Serotonin and dopamine as mediators of sensation seeking behavior. Neuropsychobiology (1996) 34:3. doi:10.1159/000119318

40. VanderVeen JW, Cohen LM, Cukrowicz KC, Trotter DR. The role of impulsivity on smoking maintenance. Nicotine $\mathrm{Tob}$ Res (2008a) 10:8. doi:10.1080/ 14622200802239330

41. VanderVeen JW, Cohen LM, Trotter DR, Collins FL Jr. Impulsivity and the role of smoking-related outcome expectancies among dependent college-aged cigarette smokers. Addict Behav (2008b) 33:8. doi:10.1016/ j.addbeh.2008.03.007

42. Liu X, Powell DK, Wang H, Gold BT, Corbly CR, Joseph JE. Functional dissociation in frontal and striatal areas for processing of positive and negative reward information. J Neurosci (2007) 27:17. doi:10.1523/JNEUROSCI.522706.2007

43. Yucel M, Lubman DI. Neurocognitive and neuroimaging evidence of behavioural dysregulation in human drug addiction: implications for diagnosis, treatment and prevention. Drug Alcohol Rev (2007) 26:1. doi:10.1080/09595230601036978
44. Lundqvist $\mathrm{T}$. Imaging cognitive deficits in drug abuse. Curr Top Behav Neurosci (2010) 3. doi:10.1007/7854_2009_26

45. Nestor L, McCabe E, Jones J, Clancy L, Garavan H. Differences in "bottom-up" and "top-down" neural activity in current and former cigarette smokers: evidence for neural substrates which may promote nicotine abstinence through increased cognitive control. Neuroimage (2011) 56:4. doi:10.1016/j.neuroimage.2011. 03.054

46. Sheffer CE, Mennemeier M, Landes RD, Bickel WK, Brackman S, Dornhoffer J, et al. Neuromodulation of delay discounting, the reflection effect, and cigarette consumption. J Subst Abuse Treat (2013). doi:10.1016/j.jsat.2013.01.012

47. Brody AL, Mandelkern MA, Olmstead RE, Jou J, Tiongson E, Allen V, et al. Neural substrates of resisting craving during cigarette cue exposure. Biol Psychiatry (2007) 62:6. doi:10.1016/ j.biopsych.2006.10.026

48. Culbertson CS, Bramen J, Cohen MS, London ED, Olmstead RE, Gan JJ, et al. Effect of bupropion treatment on brain activation induced by cigarette-related cues in smokers. Arch Gen Psychiatry (2011) 68:5. doi:10.1001/ archgenpsychiatry.2010.193

49. Hartwell KJ, Johnson KA, Li X, Myrick H, LeMatty T, George MS, et al. Neural correlates of craving and resisting craving for tobacco in nicotine dependent smokers. Addict Biol (2011) 16:4. doi:10.1111/j.13691600.2011.00340.x

50. Fagerstrom KO, Schneider NG. Measuring nicotine dependence: a review of the Fagerstrom Tolerance Questionnaire. J Behav Med (1989) 12:2. doi:10.1007/BF00846549

51. Berlin I, Singleton EG, Heishman SJ. Validity of the 12item French version of the Tobacco Craving Questionnaire in treatment-seeking smokers. Nicotine Tob Res (2010) 12:5. doi:10.1093/ntr/ntq039

52. Abrams DB, Niaura R, Brown RA, Emmons KM, Goldstein MG, Monti PM. The Tobacco Treatment Handbook: A Guide to Best Practices. New York: Guilford Press (2003).

53. Beck AT, Steer RA, Ball R, Ranieri W. Comparison of beck depression inventories -IA and -II in psychiatric outpatients. J Pers Assess (1996) 67:3. doi:10.1207/ s15327752jpa6703_13

54. Spielberger CD, Gorssuch RL, Lushene PR, Vagg PR, Jacobs GA. Manual for the State-Trait Anxiety Inventory. Consulting Psychologists Press, Inc. (1983).

55. Patton JH, Stanford MS, Barratt ES. Factor structure of the Barratt impulsiveness scale. $J$ Clin Psychol (1995) 51:6. doi:10.1002/10974679(199511)51:6<768::AIDJCLP2270510607>3.0.CO;2-1

56. Gilbert DG, Rabinovich NE. International Smoking Image Series (With Neutral Counterparts), Version 1.2. Carbondale: Southern Illinois University (1999).

57. Lang PJ, Öhman A, Vaitl D. The International Affective Picture System (Photographic Slides). Gainesville, FL: University of Florida (1988).

58. Friston KJ. Commentary and opinion: II. Statistical parametric mapping: ontology and current issues. $J$ Cereb Blood Flow Metab (1995) 15:3. doi:10.1038/jcbfm.1995.45

59. Tzourio-Mazoyer N, Landeau B, Papathanassiou D, Crivello F, Etard O, Delcroix N, et al. Automated anatomical labeling of activations in SPM using a macroscopic anatomical parcellation of the MNI MRI single-subject brain. Neuroimage (2002) 15:1. doi:10.1006/nimg.2001.0978

60. Friston KJ, Buechel C, Fink GR, Morris J, Rolls E, Dolan RJ. Psychophysiological and modulatory interactions in neuroimaging. Neuroimage (1997) 6:3. doi:10.1006/nimg.1997.0291

61. Etkin A, Egner T, Kalisch R. Emotional processing in anterior cingulate and medial prefrontal cortex. Trends Cogn Sci (2011) 15:2. doi:10.1016/j.tics.2010.11.004

62. Devinsky O, Morrell MJ, Vogt BA. Contributions of anterior cingulate cortex to behaviour. Brain (1995) 118(Pt 1): 279-306. doi:10.1093/brain/118. 1.279

63. Lieberman MD. Social Cognitive Neuroscience. New York: McGraw-Hill (2010).

64. Philippi CL, Duff MC, Denburg NL, Tranel D, Rudrauf D. Medial PFC damage abolishes the self-reference effect. J Cogn Neurosci (2012) 24:2. doi:10.1162/jocn_a_00138
65. Chua HF, Ho SS, Jasinska AJ, Polk TA, Welsh RC, Liberzon I, et al. Self-related neural response to tailored smokingcessation messages predicts quitting. Nat Neurosci (2011) 14:4 doi:10.1038/nn.2761

66. Falk EB, Berkman ET, Whalen D, Lieberman MD. Neural activity during health messaging predicts reductions in smoking above and beyond selfreport. Health Psychol (2011) 30:2. doi:10.1037/a0022259

67. Hare TA, Malmaud J, Rangel A. Focusing attention on the health aspects of foods changes value signals in vmPFC and improves dietary choice. J Neurosci (2011) 31:30. doi:10.1523/JNEUROSCI.638310.2011

68. Torta DM, Cauda F. Different functions in the cingulate cortex, a meta-analytic connectivity modeling study. Neuroimage (2011) 56:4. doi:10.1016/ j.neuroimage.2011.03.066

69. Denny BT, Kober H, Wager TD, Ochsner KN. A meta-analysis of functional neuroimaging studies of self- and other judgments reveals a spatial gradient for mentalizing in medial prefrontal cortex. J Cogn $\mathrm{Neu}$ rosci (2012) 24:8. doi:10.1162/ jocn_a_00233

70. Papachristou H, Nederkoorn C, Havermans R, van der Horst M, Jansen A. Can't stop the craving: the effect of impulsivity on cue-elicited craving for alcohol in heavy and light social drinkers. Psychopharmacology (Berl) (2012) 219:2. doi:10.1007/s00213-011-2240-5

71. Joos L, Goudriaan AE, Schmaal L, De Witte NA, Van den Brink $\mathrm{W}$, Sabbe BG, et al. The relationship between impulsivity and craving in alcohol dependent patients. Psychopharmacology (Berl) (2013) 226:2. doi:10.1007/ s00213-012-2905-8

72. Papachristou H, Nederkoorn C, Havermans R, Bongers P, Beunen S, Jansen A. Higher levels of trait impulsiveness and a less effective response inhibition are linked to more intense cueelicited craving for alcohol in alcohol-dependent patients. Psychopharmacology (Berl) (2013). doi:10.1007/s00213-013-3063-3

73. Doran N, Spring B, McChargue D. Effect of impulsivity on craving and behavioral reactivity to smoking cues. 
Psychopharmacology (Berl) (2007) 194:2. doi:10.1007/ s00213-007-0832-x

74. Doran N, Cook J, McChargue $\mathrm{D}$, Spring $\mathrm{B}$. Impulsivity and cigarette craving: differences across subtypes. Psychopharmacology (Berl) (2009) 207:3. doi:10.1007/s00213-0091661-x

75. Tziortzis D, Mahoney JJ III, Kalechstein AD, Newton TF, De la Garza R II. The relationship between impulsivity and craving in cocaine- and methamphetamine-dependent volunteers. Pharmacol Biochem Behav (2011) 98:2. doi:10.1016/j.pbb.2010.12.022

76. Stanford MS, Mathias CW, Dougherty DM, Lake SL, Anderson NE, Patton JH. Fifty years of the Barratt Impulsiveness Scale: an update and review. Pers Individ Dif (2009) 47:5. doi:10.1016/j.paid.2009.04.008

77. Bechara A, Damasio H, Damasio AR. Emotion, decision making and the orbitofrontal cortex. Cereb Cortex (2000) 10:3. doi:10.1093/cercor/10.3.295

78. Kadota H, Sekiguchi H, Takeuchi S, Miyazaki M, Kohno Y, Nakajima Y. The role of the dorsolateral prefrontal cortex in the inhibition of stereotyped responses. Exp Brain Res (2010) 203:3. doi:10.1007/s00221-010-2269-4

79. Menon V, Adleman NE, White CD, Glover GH, Reiss AL. Error-related brain activation during a Go/NoGo response inhibition task. Hum Brain Mapp (2001) 12:3. doi:10.1002/10970193(200103) 12:3<131::AIDHBM1010>3.0.CO;2-C

80. Garavan H, Ross TJ, Murphy $\mathrm{K}$, Roche RA, Stein EA. Dissociable executive functions in the dynamic control of behavior: inhibition, error detection, and correction. Neuroimage (2002) 17:1820-9. doi:10.1006/nimg.2002.1326

81. Horn NR, Dolan M, Elliott R, Deakin JF, Woodruff PW. Response inhibition and impulsivity: an fMRI study. Neuropsychologia (2003) 41:14. doi:10.1016/S00283932(03)00077-0

82. Chase HW, Eickhoff SB, Laird AR, Hogarth L. The neural basis of drug stimulus processing and craving: an activation likelihood estimation meta-analysis. Biol Psychiatry (2011) 70:8. doi:10.1016/ j.biopsych.2011.05.025
83. Kuhn S, Gallinat J. Common biology of craving across legal and illegal drugs - a quantitative meta-analysis of cue-reactivity brain response. Eur J Neurosci (2011) 33:7. doi:10.1111/j.14609568.2010.07590.x

84. Yalachkov Y, Kaiser J, Naumer MJ. Functional neuroimaging studies in addiction: multisensory drug stimuli and neural cue reactivity. Neurosci Biobehav $\operatorname{Rev}$ (2012) 36:2. doi:10.1016/ j.neubiorev.2011.12.004

85. Fransson P, Marrelec G. The precuneus/posterior cingulate cortex plays a pivotal role in the default mode network: evidence from a partial correlation network analysis. Neuroimage (2008) 42:3. doi:10.1016/ j.neuroimage.2008.05.059

86. Qin P, Northoff G. How is our self related to midline regions and the defaultmode network? Neuroimage (2011) 57:3. doi:10.1016/ j.neuroimage.2011.05.028

87. Shaurya Prakash R, De Leon AA, Klatt M, Malarkey W, Patterson B. Mindfulness disposition and default-mode network connectivity in older adults. Soc Cogn Affect Neurosci (2013) 8:1. doi:10.1093/scan/nss115

88. Kluetsch RC, Schmahl C, Niedtfeld I, Densmore M, Calhoun VD, Daniels J, et al. Alterations in default mode network connectivity during pain processing in borderline personality disorder. Arch Gen Psychiatry (2012) 69:10. doi:10.1001/ archgenpsychiatry.2012.476

89. Sato JR, Hoexter MQ, Castellanos XF, Rohde LA. Abnormal brain connectivity patterns in adults with ADHD: a coherence study. PLoS One (2012) 7:e45671. doi:10.1371/ journal.pone.0045671

90. Franzen JD, Heinrichs-Graham E, White ML, Wetzel MW, Knott NL, Wilson TW. Atypical coupling between posterior regions of the default mode network in attention-deficit/hyperactivity disorder: a pharmacomagnetoencephalography study. J Psychiatry Neurosci (2013) 38:3. doi:10.1503/jpn.120054

91. Craig AD. How do you feel now? The anterior insula and human awareness. Nat Rev Neurosci (2009) 10:1. doi:10.1038/nrn2555

92. Kurth F, Zilles K, Fox PT, Laird AR, Eickhoff SB. A link between the systems: functional differentiation and integration within the human insula revealed by meta-analysis. Brain Struct Funct (2010) 214:5-6. doi:10.1007/s00429010-0255-z

93. Benedict RH, Shucard DW, Santa Maria MP, Shucard JL, Abara JP, Coad ML, et al. Covert auditory attention generates activation in the rostral/dorsal anterior cingulate cortex. J Cogn Neurosci (2002) 14:4. doi:10.1162/08989290260045765

94. Weissman DH, Giesbrecht B, Song AW, Mangun GR, Woldorff MG. Conflict monitoring in the human anterior cingulate cortex during selective attention to global and local object features. Neuroimage (2003) 19:4. doi:10.1016/S10538119(03)00167-8

95. Weissman DH, Gopalakrishnan A, Hazlett CJ, Woldorff MG. Dorsal anterior cingulate cortex resolves conflict from distracting stimuli by boosting attention toward relevant events. Cereb Cortex (2005) 15:2. doi:10.1093/cercor/ bhh 125

96. London ED, Simon SL, Berman SM, Mandelkern MA, Lichtman AM, Bramen J, et al. Mood disturbances and regional cerebral metabolic abnormalities in recently abstinent methamphetamine abusers. Arch Gen Psychiatry (2004) 61:1. doi:10.1001/archpsyc.61.1.73

97. Beaver JD, Long CJ, Cole DM, Durcan MJ, Bannon LC, Mishra RG, et al. The effects of nicotine replacement on cognitive brain activity during smoking withdrawal studied with simultaneous fMRI/EEG. Neuropsychopharmacology (2011) 36:9. doi:10.1038/npp.2011.53

98. Li Q, Yang WC, Wang YR, Huang YF, Li W, Zhu J, et al. Abnormal function of the posterior cingulate cortex in heroin addicted users during restingstate and drug-cue stimulation task. Chin Med J (Engl) (2013a) 126:4.

99. Li X, Hartwell KJ, Owens M, Lematty T, Borckardt JJ, Hanlon CA, et al. Repetitive transcranial magnetic stimulation of the dorsolateral prefrontal cortex reduces nicotine cue craving. Biol Psychiatry (2013b) 73:8. doi:10.1016/ j.biopsych.2013.01.003

100. Albein-Urios N, Verdejo-Roman $\mathrm{J}$, Asensio S, Soriano-Mas
C, Martinez-Gonzalez JM, Verdejo-Garcia A. Re-appraisal of negative emotions in cocaine dependence: dysfunctional corticolimbic activation and connectivity. Addict Biol (2012). doi:10.1111/j.13691600.2012.00497.x

101. Barr MS, Farzan F, Wing VC, George TP, Fitzgerald PB, Daskalakis ZJ. Repetitive transcranial magnetic stimulation and drug addiction. Int Rev Psychiatry (2011) 23:5. doi:10.3109/ 09540261.2011.618827

102. Rose JE, McClernon FJ, Froeliger B, Behm FM, Preud'Homme X, Krystal AD. Repetitive transcranial magnetic stimulation of the superior frontal gyrus modulates craving for cigarettes. Biol Psychiatry (2011) 70:8. doi:10.1016/ j.biopsych.2011.05.031

103. Amiaz R, Levy D, Vainiger D, Grunhaus L, Zangen A. Repeated high-frequency transcranial magnetic stimulation over the dorsolateral prefrontal cortex reduces cigarette craving and consumption. Addiction (2009) 104:4. doi:10.1111/j.13600443.2008.02448.x

104. Taylor SF, Phan KL, Decker LR, Liberzon I. Subjective rating of emotionally salient stimuli modulates neural activity. Neuroimage (2003) 18:3. doi:10.1016/S10538119(02)00051-4

Conflict of Interest Statement: The authors declare that the research was conducted in the absence of any commercial or financial relationships that could be construed as a potential conflict of interest.

Received: 24 May 2013; accepted: 27 June 2013; published online: 16 July 2013.

Citation: Bourque J, Mendrek A, DinhWilliams L and Potvin S (2013) Neural circuitry of impulsivity in a cigarette craving paradigm. Front. Psychiatry 4:67. doi: 10.3389/fpsyt.2013.00067

This article was submitted to Frontiers in Addictive Disorders and Behavioral Dyscontrol, a specialty of Frontiers in Psychiatry.

Copyright () 2013 Bourque, Mendrek, Dinh-Williams and Potvin. This is an open-access article distributed under the terms of the Creative Commons Attribution License, which permits use, distribution and reproduction in other forums, provided the original authors and source are credited and subject to any copyright notices concerning any third-party graphics etc. 